\title{
Necrodiscursos: Discursos articulados pelas políticas da morte
}

\author{
Necrodiscourses: Speeches articulated by the politics of death \\ Necrodiscursos: Discursos articulados por la política de la muerte
}

Recebido: 17/06/2021 | Revisado: 22/06/2021 | Aceito: 23/06/2021 | Publicado: 09/07/2021

\author{
Leandro Aparecido Fonseca Missiatto \\ ORCID: https://orcid.org/0000-0002-6532-735X \\ Escola da Magistratura de Rondônia, Brasil \\ Faculdade Estácio de Pimenta Bueno, Brasil \\ E-mail: leandro_afonseca@hotmail.com
}

\begin{abstract}
Resumo
Este estudo trata da natureza necropolítica de discursos que funcionam como tecnologia da morte. Esse é um aprofundamento da obra de Achille Mbembe no que concerne à necropolítica e necropoder operando, neste caso, no campo da linguagem e discurso. Os esforços aqui conduzidos convergem para a elaboração conceitual desta tecnologia necropolítica que lança a vida de alguns aos poderes da morte. Para o desenvolvimento teórico desse trabalho utilizou-se de três conceitos chamados aqui de tríade do poder, biopoder, estado de exceção e necropoder, em uma tentativa de sedimentar as noções que orbitam e se intersecionam ao que chamo de necrodiscurso. A partir dessas fundamentações teóricas foram produzidas análises discursivas das manifestações do Presidente Jair Bolsonaro e de alguns de seus ministros, proferidos durante o ano de 2020, que dizem respeito à pandemia de COVID-19. As análises permitiram compreender que tais discursos funcionam como tecnologias da morte, uma vez que expõe aos limites existenciais as vidas das populações historicamente marginalizadas, sendo nesse sentido, necrodiscursos.
\end{abstract}

Palavras-chave: Biopoder; Estado de exceção; Necropoder; Necrodiscurso.

\begin{abstract}
This study deals with the necropolitical nature of discourses that function as technology of death. This is a deepening of the work of Achille Mbembe in what concerns necropolitics and necropower operating, in this case, in the field of language and discourse. The efforts carried out here converge to the conceptual elaboration of this necropolitical technology that throws the lives of some into the powers of death. For the theoretical development of this work, three concepts called here the triad of power, biopower, state of exception and necropower were used, in an attempt to sediment the notions that orbit and intersect in what I call necrodiscourse. Based on these theoretical foundations, discursive analyzes were produced of the statements made by President Jair Bolsonaro and some of his ministers, delivered during the year 2020, concerning the COVID-19 pandemic. The analyzes allowed us to understand that such discourses function as technologies of death, as they expose the lives of historically marginalized populations to existential limits, being in this sense, necrodiscourses.
\end{abstract}

Keywords: Biopower; Exception state; Necropower; Necrodiscourse.

\section{Resumen}

Este ensayo trata sobre la naturaleza necropolítica de los discursos que funcionan como tecnología de la muerte. Se trata de una profundización del trabajo de Achille Mbembe en lo que concierne a la necropolítica y al necropoder que opera, en este caso, en el campo del lenguaje y el discurso. Los esfuerzos aquí realizados convergen en la elaboración conceptual de esta tecnología necropolítica que arroja la vida de algunos a los poderes de la muerte. Para el desarrollo teórico de este trabajo se utilizaron tres conceptos denominados aquí tríada de poder, biopoder, estado de excepción y necropoder, en un intento de sedimentar las nociones que orbitan y se cruzan en lo que llamo necrodiscurso. A partir de estos fundamentos teóricos se elaboraron análisis discursivos de las declaraciones del presidente Jair Bolsonaro y algunos de sus ministros, pronunciadas durante el año 2020, sobre la pandemia del COVID-19. Los análisis permitieron comprender que tales discursos funcionan como tecnologías de la muerte, ya que exponen la vida de poblaciones históricamente marginadas a límites existenciales, siendo en este sentido, necrodiscursos.

Palabras clave: Biopoder; Estado de excepción; Necropoder; Necrodiscurso.

\section{Introdução}

O objetivo deste trabalho é demonstrar a existência do necrodiscurso como uma tecnologia do necropoder. A princípio retomo aquilo que considero tríade do poder, eixo fundamental para compreensão das sociedades contemporâneas: biopoder, estado de exceção e necropoder. Em seguida, será abordada a noção de necrodiscurso a partir de reflexões sobre algumas falas 
do presidente Jair Bolsonaro e de seus ministros, proferidas em plena pandemia de COVID-19 ao longo do ano de 2020. Para sustentação epistêmica e metodológica, recorreu-se aos estudos do discurso de Michel Foucault, por entendê-los eficientes para a compreensão das posições socioideológicas do sujeito falante (Foucault, 1970).

\subsection{Tríade do poder: biopoder, estado de exceção e necropoder}

Chamo esses conceitos de tríade do poder por considerar que tais elementos teóricos são fundamentais para compreensão das dinâmicas de poder nas sociedades atuais. Qualquer análise que pretenda romper com as superficialidades das relações de dominação necessitará, em algum instante, recorrer a Foucault, Agamben e Mbembe, uma vez que tais pensadores detêm em suas abordagens análises profundas e bem sedimentadas a respeito do poder, seus dispositivos e agenciadores. Para tanto, considero como ponto de partida Michel Foucault, já que sua teoria é elemento essencial para a formulação posterior das reflexões de Agambem e Mbembe.

Quando Foucault desenvolveu a teoria sobre o poder de gerência da vida das populações, a qual chamou de biopoder, tratou em demonstrar o escoamento do poder, antes totalizado na figura do soberano, para uma série de dispositivos, tecnologias e saberes que foram pulverizados na estrutura do Estado. Sua teoria se constitui, portanto, de uma minuciosa arqueologia das relações de poder cujas consequências últimas foram as conclusões que podem ser observadas em biopoder, ou seja, as análises históricas e sociais garantiram que Foucault compreendesse, ao menos conceitualmente, que o elo de transição do poder soberano para o estatal estava justamente na conversão das políticas de dominação, antes centradas na capacidade de matar, agora, na de fazer viver.

Em Vigiar e Punir (2001) Foucault trabalhou na tessitura da genealogia do poder e mais do que tentar responder o que é esse fenômeno, dedicou-se em compreender como ele é expresso materialmente na vida das sociedades, não é por menos que sua obra começa retratando a morte de Damiens, determinada pela justiça no ano de 1757. A cena não menos que aterrorizante descreve analiticamente a execução de uma sentença que se estende para além da morte, uma vez que em seu post mortem o corpo ainda será alvo de uma série de rituais que não apenas silenciava a vida, mas a educava para hierarquia dos sujeitos.

Damiens fora condenado, a 2 de março de 1757, a pedir perdão publicamente diante da poria principal da Igreja de Paris [aonde devia ser] levado e acompanhado numa carroça, nu, de camisola, carregando uma tocha de cera acesa de duas libras; [em seguida], na dita carroça, na praça de Greve, e sobre um patíbulo que aí será erguido, atenazado nos mamilos, braços, coxas e barrigas das pernas, sua mão direita segurando a faca com que cometeu o dito parricídio, queimada com fogo de enxofre, e às partes em que será atenazado se aplicarão chumbo derretido, óleo fervente, piche em fogo, cera e enxofre derretidos conjuntamente, e a seguir seu corpo será puxado e desmembrado por quatro cavalos e seus membros e corpo consumidos ao fogo, reduzidos a cinzas, e suas cinzas lançadas ao vento (Foucault, 2001, pp. 09)

Embora o assassinato seja um fenômeno humano inscrito em toda nossa história, a execução de uma vida determinada pelo soberano diferia daquelas mortes perpetradas por qualquer outra pessoa, pois para o soberano o extermínio era um direito legitimado pela posição de poder que ocupava. E como um ato associado à monarquia, matar estava inserido em toda a pompa tradicional que teatralizava as ideias em torno de si. Assim, a morte imposta pelo poder absolutista era cerimoniada e se manifestava como uma grande celebração à figura do soberano, ao mesmo tempo em que edificava uma pedagogia que educava aos vivos sobre a dinâmica do poder, nesse sentido, a morte não significava apenas a supressão da existência, mas funcionava, sobretudo, como forma de exercício de poder de subjugação dos corpos, adestramento das ideias e imposição da degradação final de vidas facilmente descartadas pelos interesses e vontades do soberano.

As análises foucaultianas dão conta que essa estrutura foi se movendo ao longo tempo à medida que valores iluministas penetravam as sociedades absolutistas e passavam a conflitar com as crenças típicas daqueles sistemas sociais. Nesse contexto, surgem os Estados-nação e dentro dessa estrutura a morte passa por profundas transformações. Segundo 
Foucault (2001), a morte deixa paulatinamente no século XVIII de ocupar os espaços coletivos em que era teatralizada como símbolo máximo do poder soberano, para resumir-se aos âmbitos privados das casas e instituições. Este abandono da morte como cerimônia coletiva de demonstração de poder se insere em um conjunto de medidas em que a soberania já não é mais manifesta pela prerrogativa de subtração de bens, valores, propriedades e até mesmo da vida humana, constituída anteriormente pela máxima "fazer morrer ou deixar viver" (Franco, 2018). Há, então, uma guinada nas manifestações do poder que a partir de meados dos anos de 1800 tira a morte dos palcos coletivos para dar protagonismo à vida na agenda política do Estado, assim, o poder já não é definido pela capacidade de matar, mas sim pela de gerenciar o viver, configurandose como um biopoder (Foucault, 2012).

O biopoder insere nos jogos de tensões de poder novos mecanismos de gestão que incidem significativamente sobre a vida e fenômenos vitais, tendo corpus privilegiado de ação as populações (Danner, 2010). Em suas aulas no ano de 1976 intituladas de É preciso defender a sociedade, Foucault define população como "corpo múltiplo, corpo com inúmeras cabeças, se não infinito pelo menos necessariamente numerável" (1997, pp. 292). Para tanto, é sobre esse corpo numerável de vidas chamado população que passam a ser destinadas as ações de poder, nesse contexto, o Estado torna-se gerenciador de processos biológicos da espécie, todavia em termos massivos, para isso faz uso de estatísticas e ferramentas epidemiológicas para prover uma verdadeira regulamentação da vida. Natalidade, mortalidade, longevidade, deslocamentos, fecundidade, entre outros, tornam-se verdadeiros dispositivos de poder.

Nesse panorama o que interessa não é a morte, mas a mortalidade, sempre medida em termos estatísticos. A morte, experiência do sujeito, limite maior de sua existencialidade, angústia final da vida humana, passa a ser fenômeno populacional, para tanto, não será mais uma categoria filosófica e humanista, pois a mesma é reduzida àquilo que possa ser mensurado e administrado.

Ela (a morte) está do lado exterior, em relação ao poder: é o que cai fora de seu domínio (...). Isso sobre o que poder tem domínio não é a morte, é a mortalidade. E nessa medida, é normal que a morte, agora, passe para o âmbito do privado, e do que há de mais privado (Foucault, 1997, pp. 221).

Ou seja, para Foucault na impossibilidade de domínio sobre a morte, os dispositivos de poder remetem-na ao anonimato de uma vida privada, tornando-a visível apenas no âmbito populacional por meio da figura da mortalidade. Logo, as adjacências da morte são incorporadas ao biopoder, constituindo-se como ferramenta a serviço da administração da vida. Surge com isso um paradoxo, pois como a morte poderia ser introduzida nestes espaços de poder em que é a vida o principal alvo de interesse estatal? Para Foucault (1997), esta contradição só é possível através daquilo que chamou de racismo de Estado.

Foucault estabelece, de certo modo, um tipo fundamental de diferença entre o racismo praticado pelos soberanos antes do século XIX e os praticados pelos Estados modernos. O racismo realizado pelos regimes totalitários fazia uso recorrente de uma narrativa que refletia a crença que o soberano, em decorrência de sua hereditariedade, já estava imbuído de prerrogativas para submeter e sujeitar à morte seus súditos (Franco, 2018). Já o racismo de Estado divergia por possuir um discurso biológico social, utilizado como estratégia para a promoção de uma luta de raças em que os princípios de segregação e extermínio se justificavam em perspectiva de se proteger a biologia superior de alguns seres humanos (Foucault, 1997). Assim, o racismo de Estado é eugenista e funciona como uma tecnologia de governo destinada a fazer viver aqueles grupos populacionais que melhor se adaptam ao perfil de produção requisitado pelo Estado moderno e capitalista (Castro-Gómez, 2007).

O olhar foucaultiano para o racismo compreende-o como ferramenta de biopoder à medida que fragmenta o continuum biológico fazendo com que seja possível a composição de hierarquias de raças, sendo as superiores passíveis a políticas de proteção, enquanto que aquelas que são alocadas nesse edifício racial em instâncias inferiores às gerências da 
morte. Nesse sentido, as raças enunciadas como subdesenvolvidas tornam-se ameaças, um perigo à integridade do corpus social, sendo seu aniquilamento a mais efetiva forma de proteção das raças legitimadas. Portanto, o racismo de Estado, não é um racismo étnico, mas sim um racismo biológico (Franco, 2018).

É interessante perceber, que enquanto o biopoder justifica suas ações sob o prisma da necessidade de se preservar vidas, nem toda vida é percebida como sujeita às biopolíticas, já que o nascimento de uma pessoa considerada de raça inferior a torna plenamente sujeita à eliminação, constituindo-se no paradoxo moderno, em que a morte daquele que incita ameaça ao projeto de uma raça superior, será totalmente justificada pelo biopoder (Alves \& Barros, 2018). Enfim, somente por meio do racismo de Estado que o paradoxo do biopoder, gestão de vida e produção da morte, é possível de simultaneamente ser articulado:

O racismo está ligado ao funcionamento de um Estado que está obrigado a se servir da raça, da eliminação das raças, e da purificação da raça para exercer seu poder soberano. A justaposição, ou melhor, o funcionamento, através do biopoder, do velho poder soberano do direito de morte implica o funcionamento, o estabelecimento e a ativação do racismo (Foucault, 1997, pp. 230).

Para garantir o pleno funcionamento do biopoder o racismo de Estado se fará presente em toda a sua estrutura, uma vez se tratar de "um racismo que uma sociedade vai exercer sobre ela mesma, sobre os próprios elementos, sobre os próprios produtos; um racismo interno, o da purificação permanente, que será uma das dimensões fundamentais da normalização social" (Foucault, 2001, pp. 53). Para tanto, utilizará de dispositivos, tecnologias e saberes de poder como o direito, a pedagogia, a medicina, a psicopatologia, etc., ferramentas que possibilitam que os interesses estatais sejam implementados, além de permitir que os cidadãos repliquem tais ideias raciais entre si, constituindo-se em uma rede altamente capilarizada de microbiopoderes raciais.

Para Alves e Barros (2018), o racismo de Estado ao normalizar as sociedades pelo biopoder, realiza um verdadeiro genocídio da própria população, excluindo, não pertencendo, não assistindo e expondo à morte às vidas não desejadas pelo Estado. Esse racismo recupera o poder soberano de decidir sobre a morte, contudo, o faz agora em termos do biopoder, tendo como justificativa resguardar as vidas das populações, ao menos daquelas que dentro dessa ótica eugênica merecem viver. Contudo, nem toda vida deve ser salva, aquelas que escapam a eugenia presente nos discursos médicos será alvo de perseguição e aniquilamento, uma vez terem escorregado para um lugar distante do normatizado pelo Estado.

Para compreender esta evasão da vida para contextos em que elas possam ser matáveis necessitamos avançar da biopolítica para a noção de estado de exceção, uma vez que Foucault pouco tratou sobre este funil em que a vida humana é evadida para locais em que sua disposição torna-se plenamente aceitável. Estamos diante do segundo elemento da tríade do poder postulado pelo italiano Giorgio Agamben que discordava de Foucault por entender que a ênfase dada pelo pensador francês de que o biopoder se destaca como uma atuação moderna estaria temporalmente equivocada. Agamben entende que a biopolítica tem nascimento com o próprio surgimento da política na pólis grega (Franco, 2018), e desde sua concepção o biopoder se relaciona intimamente com aquilo que o pensador italiano chamou de vida nиa, a vida totalmente matável e exposta à morte, imposta a um tipo de exclusão (Agamben, 2002).

Suas investigações indicaram que não a biopolítica, mas sim aquilo que chamou de estado de exceção, é a novidade da modernidade (Souza, 2018). Agamben considera que o estado de exceção foi uma estratégia resguardada no ordenamento jurídico dos Estados-nação que articularam a possibilidade de o governo, mediante excepcionalidades, restituir o poder soberano, suspendendo a lei, subtraindo direitos e com isso, indiferenciar às subjetividades que passam a ser regidas pelo governo com total controle sobre a morte e os destinos das pessoas. A ideia de Agamben é de que o biopoder por si só não é 
capaz de explicar a capacidade de o Estado promover verdadeiras execuções em massas sem que tenha que construir espaços em que possa agir com plenos poderes de soberano, para tanto necessita do amparo do estado de exceção.

No estado de exceção as garantias de direitos são diluídas ante a justificativa da necessidade de se conter uma crise ou ameaça ao Estado. Logo, o estado de exceção, só possível em virtude do discurso biopolítico de proteção às vidas e da nação, todavia, sua operacionalização ocorrerá justamente no extermínio de vidas consideradas como uma ameaça ao projeto de biopoder do Estado. Exemplo disso foi o holocausto da Segunda Guerra Mundial, em que o discurso nazista de aniquilamento judaico se sustentava na imagem (meticulosamente elaborada) do judeu como um risco à segurança do trabalho, aos direitos e, sobretudo, a pureza da raça ariana (Menezes, 2019), o que fez daquele povo residente na Alemanha um verdadeiro inimigo do Estado.

É certo que o estado de exceção ocorre não por ausência da lei, mas justamente pela existência de um ordenamento jurídico que lhe privilegia o uso de ferramentas para exterminar aqueles que ocuparem o lugar dos indesejados pelo Estado. Para tornar ainda mais táteis suas ideias, Agamben concebe a noção de campo, lugar em que, sendo declarado o estado de exceção, o Estado age de modo a determinar a morte de seus inimigos e até mesmo de seus concidadãos.

Portanto, o campo corresponde:

[...] uma localização sem ordenamento (o campo como espaço permanente de exceção). O sistema político não ordena mais as formas de vida e normas jurídicas num espaço determinado, mas contém em seu interior uma localização deslocadora que o excede, no qual toda forma de vida e toda norma pode ser virtualmente capturada. O campo como localização deslocadora é a matriz oculta da política em que ainda vivemos, a qual devemos aprender a reconhecer através de todas as suas metamorfose (Agamben, 2015 pp. 47).

Nota-se que Agamben entende estes campos de atuação do estado de exceção como ilhas para execução humana. Nesse sentido, podemos tomar como exemplo a situação das favelas brasileiras conforme descrito por Marielle Franco (2014) ao demonstrar que as Unidades de Polícia Pacificadora (UPP) nas comunidades do Rio de Janeiro agiam pelo poder de matar e não de pacificar, por meio da dominação de suas populações vistas intermitentemente como suspeitas e como uma ameaça ao Estado. As ações de morte são tão frequentes nesses territórios que podemos considerar as favelas como campos em que vigora intermitentemente o estado de exceção, onde direitos fundamentais à vida são constantemente dissolvidos, garantindo o extermínio populacional por ação de milícias, tráfico, ou mesmo pela violência policial.

Embora Foucault e Agamben tenham contribuído grandemente para compreensão do funcionamento do poder em tempos modernos, a atuação filosófica desses pensadores esteve circunscrita à Europa. Suas articulações teóricas dizem respeito a este lugar do qual faziam parte, com pouco espaço para aquilo que acontecia para além dos limites europeus. Ou seja, por mais que a Europa estivesse chocada com as atrocidades executadas pelo regime nazista, não fora capaz de olhar para as Américas e Áfricas, que há muito tempo eram assoladas por abusos, dominações, explorações e assassinatos em massa, elementos praticamente silenciados nas obras de Foucault e Agamben, o que gerou fortes críticas às suas teorias (Stoler, 1995; Mignolo, 2010; Losurdo, 2011).

É nesse en passant teórico produzido por Foucault e Agamben que se localiza a atuação de Achille Mbembe. Ao olhar para as realidades de exploração, dominação e opressão das Áfricas e das Américas, o pensador camaronês, articulou um novo saber, o de necropolítica, conceito complementar à biopolítica e estado de exceção, fechando a tríade do poder: biopoder estado de exceção - necropolítica.

No ensaio Necropolítica: biopoder, soberania, estado de exceção, política de morte (2016), Achille Mbembe inicia suas discussões questionando a capacidade do conceito de biopoder responder questões como: "se consideramos a política uma forma de guerra, devemos perguntar: que lugar é dado à vida, à morte e ao corpo humano (em especial o corpo ferido ou morto)? Como eles estão inscritos na ordem de poder?” (Mbembe, 2016, pp. 126). 
Mbembe entente que a teoria de biopoder é insuficiente para responder a esses questionamentos e considera que o principal equívoco de Foucault e Agamben diz respeito ao entendimento de que havia certa uniformidade nas populações, o que fez com que suas teorias se restringissem às democracias modernas e a ideia de que esse regime político é formado por homens e mulheres livres, regidos pelo princípio de igualdade (Mbembe, 2016).

Mbembe destaca que em todas as sociedades haverá comunidades inteiras que não se enquadram nos elementos normatizantes em que as teorias foucaultianas e agambentianas se fundamentaram. Tomemos como exemplo a Declaração dos Direitos do Homem e do Cidadão, de 1789. O próprio título da declaração exige pensar quem é a pessoa que faz jus ao título de cidadania, pois é sob este solo conceitual que emergem os direitos humanos. Para responder a esta questão os Estados-nação elaboraram uma série de normativas que definiam a cidadania a partir do nascimento em uma posição geográfica. Contudo com o fim da Primeira Guerra Mundial havia na Europa-central uma legião de pessoas refugiadas que formavam os sem pátrias, oriundos de impérios que simplesmente desapareceram como o russo, austro-húngaro e otomano, eram cidadãos de lugar algum (Arendt, 2012). Em seu livro, Estranhos à nossa porta, Zygmunt Bauman (2017) aborda o mesmo problema, mas agora sob a lente da crise migratória na Europa, demonstrando que os refugiados constituem uma categoria de pessoas, que dentro dos campos de refúgio, tornam-se vidas inominadas com seus direitos de cidadania suspendidos. O ingresso de imigrantes nos países de destino quase que sempre são marcados por uma série de violências aos direitos humanos perpetrados pelo Estado sob o fundamento do discurso protecionista que alardeia a necessidade de cuidar da vida de seus cidadãos, fazendo com que os imigrantes rapidamente se transformem em verdadeiros inimigos do Estado. Ou seja, a cidadania por si só não é capaz de garantir direito, uma vez que a vida é muito mais fluida que a rigidez de conceitos. Possas nascem em lugares específicos, mas migram para outros tantos lugares fazendo mover conceitos e dando elasticidades a situações concretas do viver. A homogeneização da vida em categorias, semelhantes às utilizadas por Foucault e Agambem não possibilitam analisar situações complexas como as que ocorrem na atualidade, ou aquelas que desde o século XVI vem ocorrendo no Sul-global.

Nesse sentido, Mbembe admite que a primeira experimentação da inimizade proposta pela biopolítica do estado de exceção foi no sistema de escravagista produzido pelo colonialismo. Para ele, em muitos sentidos, o sistema plantation desenvolvido para colonização de novas terras caracteriza de modo emblemático o estado de exceção (Mbembe, 2016). O escravo nesse regime perdia mais que a liberdade, sua casa, nacionalidade, identidade, status político, ou o direito de pertencer e ser parte de uma nação. Perdia, sobretudo ao direito de ser alguém na dimensão mais profunda da existencialidade humana. Como vidas, negros e negras escravizadas não tinham valor algum, seu valor se dava apenas mediante sua objetificação que os colocava como reféns nos campos constituídos pelo sistema plantation.

Nesses campos de exceção formados pelo sistema de colonização, o colonizador agia como verdadeiro soberano, decidindo sobre a manutenção da vida ou destinando seus escravos à morte. Impor aos negros uma vida inteira nos limites dos campos de exceção só era possível graças a um conjunto complexo de leis, ideologias e políticas que os despiam de suas humanidades, dispondo-os de seus direitos e conduzindo-os a total discricionariedade de seus dominadores. Mbembe demonstra com isso que os sistemas colonialistas implantados nas Américas e Áfricas agiam verdadeiramente como estados de exceção, por gerirem o poder por meio de antagonismos. Enquanto o biopoder era utilizado como recurso para administração da vida do colonizador e seus descendentes, uma outra política atuava na apropriação dos corpos e vidas das pessoas que eram matáveis, dispensáveis em virtude de sua objetificação na forma de propriedade, política chamada por ele de necropoder.

O necropoder é, desse modo, o poder utilizado para gerir as mais diversificadas formas de impor ou expor à morte as vidas que são consideradas de baixo valor pelo Estado ou por outras instituições. Trata-se de uma força que não se traduz meramente pelo oposto do biopoder, mas uma complexa rede de dispositivos, tecnologias e saberes próprios que antes mesmo do Estado moderno já agiam para liquidação de vidas humanas (Mbembe, 2016). A sensibilidade de Mbembe o fez percorrer pela história de colonização e neocolonização das Américas e Áfricas, bem como aos eventos atuais da modernidade, para 
evidenciar a operacionalização da necropolítica em recrutar e desenvolver certas tecnologias para agirem no assassinato em massa daqueles cidadãos despidos de direitos, detentores da vida nua concebida por Agamben. Ou seja, a morte deliberada de alguns não pode ser inscrita apenas em uma agenda de proteção de outros por meio do biopoder, é mais que isso. A morte planejada, gerenciada e executada de várias vidas é uma ocorrência pertencente a um fenômeno próprio que evidencia um tipo específico de poder que se sustenta na imposição e administração da morte de algumas pessoas. Tais constatações permitem, em níveis mais concretos, admitir que a constatação do biopoder e estado de exceção, embora plausíveis, não são suficientes para representar a complexidade da vida e da morte das populações dominadas, fazendo que irrompa a necessidade de uma dimensão específica para análises desses fenômenos, como a proposta por Mbembe.

Enfim, tendo compreendido a natureza dessa tríade do poder, composta por conceitos que carregam em comum, estudos sobre o poder, racismo, vida e morte, podemos avançar rumo ao nosso objetivo que é o de contribuir com a teoria de necropolítica com a inclusão de um conceito capaz de representar o funcionamento das engrenagens da morte por meio de discursos, o qual chamo de necrodiscurso.

\section{Metodologia}

Este é um estudo qualitativo cujo objetivo central foi o de demonstrar a existência de necrodiscursos, ou seja, discursos de morte. Para que fosse viável o alcance desse fim, foram realizadas análises discursivas de narrativas do Presidente da República, Jair Bolsonaro, e alguns de seus ministros, proferidas durante o ano de 2020 a respeito da pandemia de COVID19. Como princípio metodológico utilizou-se da Análise do Discurso de abordagem foucaultiana (1970).

\section{Resultados e Discussão}

\subsection{Necrodiscurso: discursos de morte e sua expressão no Brasil durante a pandemia de COVID-19}

Em 11 de março de 2020 a Organização Mundial de Saúde (OMS) classificou o surto de doença causado pelo novo coronavírus (COVID-19) como uma pandemia. Desde então, o mundo parou e este é o problema comum a todos os povos. Vidas aprisionadas em suas próprias casas, economias sucumbindo, relações de trabalho afrouxadas e com perdas significativas de direitos trabalhistas compõe o cenário de pânico e temor no qual estamos inseridos.

No Brasil o quadro é ainda mais crítico. Até o momento em que escrevo este estudo são mais de 450 mil mortes, sem expectativas de relevante recrudescimento nas próximas semanas de tais números. Além de todas essas perdas, o país enfrenta um dos seus piores cenários sociais das últimas décadas. O aumento da fome (Cruz, 2020), desemprego (Trovão, 2020) e evasão escolar (UNCME, 2020), são reflexos das conexões mortíferas da pandemia com as desigualdades historicamente estruturadas. Inúmeros dados estatísticos mostram que as populações indígenas, negras, periféricas e pobres são as mais vulneráveis à mortalidade por COVID-19 (Demenech et al., 2020; Peres, 2020; Rocha \& Porto, 2020; Santos et al., 2020). Nesse contexto, fica evidente que as forças necropolíticas agem sobre as vidas secularmente disponibilizadas à evasão do existir, sendo, no caso do Brasil, articuladas, sobretudo por discursos que operam pelo agenciamento das práticas de morte sobre as populações subalternizadas. Pretendo aqui demonstrar como tais discursos são utilizados para conduzir algumas vidas aos domínios da morte, sendo, portanto, políticas concretas que disseminam à lógica da maldade que segregam os que têm direito de viver daqueles que são descartados aos abismos da morte. Para tanto, recorro a estudos que evidenciam a capacidade dos discursos agirem como percursos de condução de ideologias, saberes e poder, elementos que se entrelaçam na materialidade da vida. A ideia aqui é entender como metodologicamente viável analisar os discursos por meio de suas entrelinhas e compreender, com isso, suas subjacências ideológicas, históricas e políticas. 
Em A ordem do discurso (1970), Foucault se perguntou como poderíamos compreender os caminhos percorridos pelo poder, por meio dos discursos, com a finalidade de que operassem nos sentidos de verdade. A princípio o objetivo de Foucault não era o de desenvolver um método linguístico de pesquisa e de entendimento do discurso, seu objeto de interesse ainda persistia nas relações e tensionamentos produzidos pelo poder, contudo, deixou evidente que não há, principalmente nas sociedades modernas, a possibilidade de compreensão das articulações do poder sem que se passe pelo campo linguístico do discurso. Isso, graças à natureza dinâmica dos discursos que sempre deixam vestígios capazes de conduzir aos sentidos que rompem com a mera significação das palavras, sendo, portanto, uma manifestação sócio-histórica do sujeito e da comunidade que discursa (Orlandi, 2007). Em sua obra Arqueologia do saber (2008) Foucault desenvolve de modo mais sofisticado a função da linguagem e discurso como tecnologias de poder, e a importância dessa dimensão:

[...] consiste em não mais tratar os discursos como conjuntos de signos (elementos significantes que remetem a conteúdos ou a representações), mas como práticas que formam sistematicamente os objetos de que falam. Certamente os discursos são feitos de signos; mas o que fazem é mais que utilizar esses signos para designar coisas. É esse mais que os torna irredutível à língua e ao ato de fala. É esse "mais" que é preciso fazer aparecer e que é preciso descrever (Foucault, 2008, pp. 55).

Esse algo a "mais" implícito nos discursos funciona para Foucault como elemento linguístico que dispõem de uma relação material de saberes que operam a serviço do poder. A linguagem passa a agir sob uma perspectiva não meramente codificante, mas, sobretudo como acontecimento sócio-histórico (Orlandi, 2007), transportando nas palavras ideologias que são transmitidas por meio dos sentidos atribuídos por aqueles que ocupam funções de poder. E essas ideologias, por sua vez, são concretas o suficiente a ponto de definirem, em últimas condições, quem tem o direito ao trabalho protegido e aquele que deverá ser expor ao trabalho insalubre, quem é que come e quem passa fome, quem tem o direito natural à saúde e a educação e a quem esses direitos são disputados, ou seja, a ideologia traduzida nos discursos orquestra a vida concreta das populações ampliando ou produzindo as desigualdades.

Para tanto, em Foucault (2008) o discurso proferido tem sempre uma função política, não podendo ser dicotomizado do poder. A linguagem é concebida, nesse sentido, como território de conflitos, de ambiguidades e de disputas que se sustentam não apenas no contexto imediato do sujeito falante, mas em toda ancestralidade de sua fala que tende a reativar memórias discursivas que foram engendradas por verdadeiras políticas da lembrança e do esquecimento. Portanto, toda fala abarca aquilo que ouviu, bem como aquilo que ouviu e foi tensionada a esquecer, ou mesmo aquilo que sequer ouviu. A linguagem é lugar de presenças e de ausências que são determinadas pelas disputas de poder que agem principalmente no sucumbimento das percepções dos que são dominados. Ou seja, o discurso é dotado de um saber ancestral determinado por aquilo que se poderia, conseguiria ou se pretendia falar em determinadas épocas, desse modo, os discursos refletem verdadeiras memórias da construção e funcionamento dos sistemas de poder.

Fica evidente que os discursos são políticos e sendo políticos atuam a serviço do poder, para tanto, torna-se absolutamente fácil inferir que, em havendo dois sistemas paralelos de poder, o biopoder e o necropoder, há, portanto discursos específicos pertencentes a essas dimensões. Essa é a ideia nuclear que nos permite afirmar que pelo caminho da linguagem do necropoder há a formação de discursos de morte que podemos chamar de necrodiscurso. Isto é, tipos de discursos que imperam como justificativas para sobrestado da lei e legitimação do estado de exceção, com refletida ação sobre populações nuas em direitos e passíveis à morte, executando, desse modo, o projeto de dominação, apropriação e aniquilamento daqueles que são revestidos pela imagem do inimigo ou de cidadãos dispensáveis ao Estado. Bem como práticas discursivas que agenciam políticas para produção da morte de grupos específicos, ou mesmo garante a ausência de biopolíticas que acabam por cooperar para a vulnerabilização à morte violenta, desprotegida e indisponível ao luto e reconhecimento. 
Chimamanda Ngozi Adichie, escritora nigeriana, em O perigo de uma única história (2009), demonstra a partir de suas experiências que visões monolíticas sobre a África se moldaram com o pensamento eurocêntrico e foram difundidas secularmente por meio de discursos que, geração após geração, trataram de garantir a manutenção da hierarquia das raças. Conta Ngozi sobre sua experiência ao chegar aos Estados Unidos para estudar de como foi surpreendida pela percepção de uma colega de quarto sobre sua terra:

[...] ela sentiu pena de mim antes mesmo de ter me visto. Sua posição padrão para comigo, como uma africana, era um tipo de arrogância bem intencionada, piedade. Minha colega de quarto tinha uma única história sobre a África. Uma única história de catástrofe. Nessa única história não havia possibilidade de os africanos serem iguais a ela, de jeito nenhum. Nenhuma possibilidade de sentimentos mais complexos do que piedade. Nenhuma possibilidade de uma conexão como humanos iguais (Ngozi, 2009, pp. 02).

Ngozi demonstra o impacto secular do necrodiscurso do colonizador que transmuta a figura humana do colonizado para além do tempo específico da colonização. Seu ardil efeito é tornar o colonizado um eterno sujeito passivo à dominação e mortificação. Ainda nesse sentido, Aimé Césaire em Discurso sobre o colonialismo (1978) acusa a capacidade do colonialismo em disseminar o racismo através de discursos pejorativos sobre os negros em perspectiva de os descivilizar. Embora Césaire não trate do necropoder, sua obra demonstra o funcionamento dos sistemas de colonização como uma arte de dominar, explorar e matar tendo como natureza fundamental o discurso das raças.

Outra evidente manifestação do discurso do necropoder de colonização se manifesta nas narrativas concernentes à colonização da Amazônia brasileira. Em artigo intitulado O discurso colonizador na elaboração de projetos: uma limitação ao desenvolvimento sustentável na Amazônia brasileira, os autores discutem a ocupação do estado de Rondônia e o impacto na formação populacional do estado e seus reflexos no desmatamento da floresta, segundo eles a destruição do meio ambiente é favorecida pelo discurso colonialista de dominação da terra, conquista dos espaços em vista do desenvolvimento econômico (Costa et al., 2009). Portanto, a dominação dos territórios amazônicos se encontra entrelaçada a uma série de discursos que enquanto difundem a ideia de progresso e desenvolvimento, colocam em prática projetos de devastação da natureza e amplificação das desigualdades produzidas pelo sistema capitalista (Acosta, 2016).

Logo, a articulação entre discurso e morte como tecnologia do necropoder se revela presente desde épocas da colonização e mantém-se modernidade afora. De modo sutil Mbembe em seu ensaio Necropolítica, concebe o discurso como forma de compreensão da realidade:

[...] experiências contemporâneas de destruição humana sugerem que é possível desenvolver uma leitura da política, da soberania e do sujeito, diferente daquela que herdamos do discurso filosófico da modernidade. Em vez de considerar a razão verdade do sujeito, podemos olhar para outras categorias fundadoras menos abstratas e mais táteis, tais como a vida e a morte (Mbembe, 2016, pp 125).

Mbembe admite, mesmo sem fazer aprofundamento na dimensão discursiva da necropolítica a impossibilidade de se analisar a política, a soberania e o sujeito sem que se faça uso das referências eurocêntricas e de suas democracias homogeneizadas. Nesse espaço teórico e filosófico apresentado por Mbembe é que se insere o necrodiscurso, em que uma vasta gama de discursividades carregadas por ideologias, cuja finalidade é justificar as práticas mortíferas do Estado, ou por agentes indiretamente chancelados por ele, são executadas contra os concidadãos de um país. Tais discursos são muito mais nucleares que a própria ação de matar, pois agem antecipadamente na fomentação do estado de exceção, cabendo a eles a função de fertilizar os espaços de poder para posterior operacionalização dos demais recursos de extermínio.

Tomemos como exemplo o caso recente do Brasil. Em 20 de março de 2020, poucos dias depois da OMS declarar a doença por COVID-19 como uma pandemia o Congresso Nacional a pedido do Presidente da República, Jair Bolsonaro, reconheceu o estado de calamidade pública por meio do Decreto Legislativo nº 06 de 2020 (Brasil, 2020). Tal decreto permitiu 
que o executivo gastasse mais do que estava previsto sem atender às metas fiscais, o objetivo era que estes gastos estivessem voltados ao enfrentamento do coronavírus.

A princípio, a medida adotada pelo governo surge como uma engrenagem do biopoder, já que operava no sentido de defender a vida das populações. Todavia, logo após declarar estado de calamidade pública, o que sugeriria o reconhecimento da gravidade da situação, o presidente Bolsonaro, por incontáveis vezes, se pronunciou diminuindo os danos em decorrência do COVID-19. Em 24 de março de 2020, a primeira vez em que se refere à gravidade da doença, Bolsonaro afirma, em discurso televisionado, que:

O que se passa no mundo têm mostrado que o grupo de risco é o das pessoas acima dos 60 anos. Então, por que fechar escolas? Raros são os casos fatais de pessoas sãs, com menos de 40 anos de idade. Noventa por cento de nós não teremos qualquer manifestação, caso se contamine. No meu caso particular, pelo meu histórico de atleta, caso fosse contaminado pelo vírus não precisaria me preocupar, nada sentiria ou seria quando muito, acometido de uma gripezinha ou resfriadinho (Radioagência Nacional, 2020).

Em outra ocasião, o presidente Bolsonaro declarou que o "brasileiro tem que ser estudado. Ele não pega nada. Você vê o cara pulando em esgoto ali, sai, mergulha, tá certo? e não acontece nada com ele. Eu acho até que muita gente já foi infectada no brasil, há poucas semanas ou meses, e ele já tem anticorpos que ajuda a não proliferar isso daí” (Gomes, 2020). Falas como estas evidenciam o paradoxo discursivo que se constrói ante a instalação do estado de calamidade pública e a sequência de manifestações contrárias a sua justificativa, em que a pandemia é minimizada em todos seus termos, exceto em um, o econômico.

Os discursos presidenciais, que insistem com a quebra do isolamento social, indicam que a suspensão das metas fiscais não diz respeito à proteção da vida de todos, pelo contrário, diz respeito à proteção do capital, nesse contexto, uma grande quantidade de pessoas que não se insere no conjunto de garantias forjadas pela noção de sujeito de direitos, ver-se-á exposta à pandemia sem as mínimas condições de proteger-se. Esta população sofrerá com os ditames do soberano que não agirá de nenhum modo para garantir-lhes a vida, e sim a morte.

Em outro discurso necropolítico no dia 08 de abril de 2020, o presidente volta a conclamar as pessoas que se encontravam em isolamento social a retornarem às suas funções normais no trabalho. Nessa ocasião Bolsonaro justifica o retorno ao trabalho ao dizer: "Como afirmou o diretor-geral da Organização Mundial da Saúde, cada país tem suas particularidades, ou seja, a solução não é a mesma para todos. Os mais humildes [grifos nossos] não podem deixar de se locomover para buscar o seu pão de cada dia" (G1, 2020). Nessa fala Jair Bolsonaro evidencia quem são as pessoas que devem ser expostas ao vírus saindo às ruas para trabalhar; os mais pobres.

O discurso do trabalho como fundamento do necropoder já foi ilustrado na obra A banalização da injustiça social (2000) de Christophe Dejours, em seu livro o autor retoma Hannah Arendt para desenvolver a ideia de que não apenas a maldade pode ser banalizada, mas também a injustiça social. Para Dejours, conviver com a injustiça social não é algo fácil, para tanto, é preciso desenvolver a crença de que não há culpa moral ou social pelo sofrimento do outro, nesse sentido, por meio do discurso da meritocracia, da responsabilização pessoal pelo fracasso, a injustiça social se torna aceitável nas sociedades.

Dejours entende que esta banalização ocorre, sobretudo, no âmbito do trabalho, haja a vista a importância que o mesmo possui para constituição da dignidade e saúde humana. Para ele, a precarização do trabalho, através da flexibilização de suas relações permite a produção do discurso de que se é preciso defender os postos de trabalho e a economia, caso contrário ninguém sobreviveria. Dejours trata ainda de como essas narrativas de controle operam para que no âmbito do trabalho, as perdas de direitos trabalhistas ocorram com mínimos desgastes aos órgãos de controle e gerência do trabalho. Ou seja, sob a premissa de sustentar postos de trabalho, o Estado viola direitos trabalhistas recrudescendo garantias historicamente 
conquistadas, produzindo desse modo, uma alienígena ambiguidade: precarização do trabalho para proteger o trabalho. Fica, então, evidente que não se trata de proteger o humano que trabalha, mas o trabalho em si mesmo, pois é ele que opera para o enriquecimento de alguns. $\mathrm{O}$ fato é que, a questão posta como urgente sorrateiramente oculta o fundamento substancial do conflito - a quem serão reservados os postos de trabalho com maiores garantias sociais? - ou seja, a proclamação do terrorismo trabalhista tende a retirar de cena o problema que persiste na histórica legitimização de grupos tradicionais no trabalho socialmente protegido, enquanto que identidades subalternizadas são recorrentemente tensionadas a abismos de desigualdades.

Enfim, discursos como o de Bolsonaro que afirmam que os mais pobres devem se arriscar em meio a uma pandemia tão letal como a de COVID-19, ilustram a natureza pérfida com que a necropolítica age impondo a grupos específicos pessoas negras, indígenas, migrantes, mulheres, pobres, etc. - escolhas do tipo, morrer ou morrer. Para tanto, ao discursar contra o isolamento social, justamente no momento em que aumentava o número de contágio e de morte (Bathia, 2020), o executivo nacional expunha, sem nenhum tipo de pudor, a quem são dirigidas as necropolíticas: trabalhadoras e trabalhadores que fazem uso de transporte coletivo, mulheres e homens que contam com o mínimo para sobreviver, moradores das periferias nacionais, populações negras, indígenas, migrantes, etc. Enquanto isso, um grupo restrito da sociedade passava a ser alvo das biopolíticas: servidores públicos, pessoas brancas, burgueses, etc. já que a elas era garantido o direito ao homeoffice, proteções salariais, manutenção de planos de saúde, enfim, a uma série de mecanismos que agem para proteção da vida. Nesse sentido, o que vigora é o paralelismo de dois mundos - o do necropoder e o do biopoder - ambos atuando em espaços diferentes, mas ao mesmo tempo, entrelaçados pela secular diferença ontológica ${ }^{1}$ que atua na distinção, simbólica e concreta, de quem são os humanos e os sub-humanos do mundo, fundamento substancial para segregação dos territórios do necropoder e do biopoder.

Contudo, cabe destacar que os grupos subalternizados já se encontravam expostos aos riscos da morte muito antes da pandemia, como bem observado por Abdias do Nascimento ao tratar do genocídio das populações negras no Brasil (Nascimento, 1978) e o documento apresentado ao Supremo Tribunal Federal elaborado pela Articulação dos Povos Indígenas do Brasil (APIB) alertando sobre o permanente extermínio desses povos indígenas (APIB, 2020), ou seja, o que ocorre é um aprofundamento do extermínio que encontrou na pandemia de COVID-19, os meios naturais para isso. Nesse sentido, vigora em nosso tempo a recuperação nua e crua do poder soberano que efetiva a morte dos dissidentes do Estado, sem nenhum tipo de pudor.

Observe o seguinte quadro: quando retomamos o prelúdio de Vigiar e Punir em que Foucault destaca a morte de Damiens para além do extermínio da vida, mas também na sua extensão em um post mortem violentamente degradante e o comparamos com o Brasil atual, em que a morte se tornou uma execução pública, assistida por todos, e sem possibilidade de luto, percebe-se que as diferenças residem nos recursos utilizados e não no fato em sim, enquanto um usava a forca, outro usa a asfixia pela falta de oxigênio em leitos hospitalares, a adoção de remédios sem eficácia comprovada, resistências às medias sanitárias eficientes como o uso de máscaras, etc. Esse foi o caso, por exemplo, da cidade de Manaus, e de várias outras cidades brasileiras, em que uma crise anunciada da falta de oxigênio elevou brutalmente a quantidade de vítimas de COVID19. O número extraordinário de mortos colapsou os serviços mortuários que chegou a prever sepultamento dos corpos em sacos plásticos, depositados em valas coletivas (Estadão, 2020). Ou seja, a morte não é apenas uma execução do corpo socialmente disponível ao aniquilamento, mas um processo que mesmo depois de despir em vida o sujeito de dignidade, o faz

\footnotetext{
${ }^{1}$ Diferença ontológica é um conceito desenvolvido por leandro fonseca missiatto que diz respeito à ruptura do continuum humano, elemento fundamental para produção tanto da diferença colonial quanto da colonialidade. Segundo o autor a diferença ontológica ao fraturar a humanidade permitiu sua hierarquização em classes e categorias. Embora essa ideia se manifeste com pleno vigor no encontro colonial não nasceu necessariamente desse evento, estando impressa na história dos povos europeus pré-modernos, por meio de sua tradição em desqualificar, perseguir, dominar e extinguir às diferenças. Ver: missiatto, leandro fonseca. (2020). Diferença ontológica: a dicotomia humana como espaço de produção da diferença colonial. Revistas epistemologias do sul, v. 04, n. 01, pp. 20-45.
} 
em seu pós-vida, retirando-lhe o direito a um sepultamento honrado, ao luto dos familiares, enfim a uma memória afetiva e não degradante.

Para tanto, fica evidente que o necrodiscurso se encontra atualmente difundido no atual governo que tem utilizado o Estado para o extermínio das diferenças incômodas ao projeto hegemônico de uma sociedade normatizada. Nesse cenário toda vida não legitimada pelos gestores do poder se encontra em risco, como se pode evidentemente perceber em discursos ministeriais proferidos contra a Natureza e os povos das florestas. Em reunião ministerial do dia 22 de abril de 2020, o ministro do Meio Ambiente, Ricardo Salles, afirmou que "Precisa ter um esforço nosso aqui, enquanto estamos nesse momento de tranquilidade no aspecto de cobertura de imprensa, porque só se fala de Covid, e ir passando a boiada, e mudando todo o regramento ambiental, e simplificando normas" (Shalders, 2020). A famosa expressão "passar a boiada" reflete o interesse governista em avançar com o projeto de devastação do meio ambiente e mercantilização da vida. Não por acaso os índices de desmatamento na Amazônia atingiram os maiores níveis nos anos de aprofundamento da crise de COVID-19. Nesse sentido o necrodiscurso é uma tecnologia da morte não apenas humana, mas de toda a vida que é apreendida pelo sistema capitalista como uma possibilidade direta ou indireta para seu enriquecimento.

Essa lógica de perversa aniquilação da Natureza e daqueles que a defendem também pode ser observado em outro necrodiscurso, o articulado pelo então ministro da educação, Abraham Weintraub, em mesma reunião ministerial do "passar a boiada" do Salles. Weintraub expressa verdadeiro ódio aos povos originário ao dizer "odeio o termo 'povos indígenas', odeio esse termo. Odeio. O ‘povo cigano'. Só tem um povo nesse país. Quer, quer. Não quer, sai de ré. É povo brasileiro, só tem um. Pode ser preto, pode ser branco, pode ser japonês, pode ser descendente de índio, mas tem que ser brasileiro, pô! Acabar com esse negócio de povos e privilégios" (Leitão, 2020). O racismo expresso na fala do ministro da educação manifesta a natureza mortífera de seu discurso que coopera com os sentimentos e ações ofensivas aos povos originários, pressionando-os ainda mais para o abismo do extermínio. Nesse sentido, o que se têm, é um cenário de difícil contestação em que os discursos expressam de modo visceral as políticas de morte produzidas no atual governo.

Assim, enquanto necrodiscursos continuam a ser emitidos largamente pelo presidente da República e seus correligionários, a vida da Natureza e das minorias encontram-se ainda mais vulneráveis, precarizadas e sujeitas à morte antecipada, desassistida, inumana e violenta. Esse retrato nos permite inferir sem nenhum tipo de reticência que os discursos necropolíticos executados no Brasil não se referem a categorias abstratas da linguagem, pelo contrário, tais discursos operam no campo concreto, mobilizando políticas, refletindo posicionamentos ideológicos, desmontando ou edificando cenários sociais que favoreçam o extermínio de grupos socialmente minorizados.

Enfim, como foi demonstrado o necrodiscurso se revela como um mecanismo material que age correlatamente com o necropoder, sendo ele mesmo uma necropolítica que pactuada com valores ultraconservadores age para a efetivação de tecnologias, saberes, e dispositivos diversos para a dizimação de populações inteiras. O necrodiscurso é, nesse sentido, uma tecnologia do necropoder que tem sua eficácia no convencimento, sustentação e angariamento de apoios para que o detentor do poder possa efetivar sua gestão de morte.

\section{Conclusão}

Neste estudo argumentou-se sobre a constituição de uma tecnologia da necropolítica e necropoder que não fora contemplada diretamente na obra do pensador camaronês Achille Mbembe, mas que se encontra impressa adjacentemente em seus estudos: o necrodiscurso. Tomando como exemplo o Brasil durante a crise sanitária e humanitária da Covid-19, e os discursos dos representantes do atual governo, propomos que o necrodiscurso, atua por meio de uma linguagem que articula ideias e valores voltados para contemplação da morte de certas populações, fertilizando terrenos para que o Estado possa conduzir determinadas vidas aos ditames da morte. Portanto, necrodiscurso é um dispositivo linguístico que expressa de modo 
mais elementar as ideologias e políticas que operam a favor do necropoder, sendo, desse modo, um mecanismo a serviço do extermínio de grupos, povos, e mesmo da Natureza.

Compreender a linguagem do poder a partir dessa nova categoria do discurso, contribui para que avancemos na desocultização dos artefatos do poder e de suas gerências de morte, permitindo seu enfrentamento nas muitas dimensões que essa realidade complexa de imposição da dominação, subalternização e aniquilamento da vida, assim o exige.

\section{Referências}

Adichie, C. N. (2009). O perigo de uma única história. https://www2.ifmg.edu.br/governadorvaladares/noticias/adelia-a-poesia-e-a-vida-convite-para-o-3oencontro-do-dialogos/o-perigo-de-uma-historia-unica-chimamanda-ngozi-adichie-pdf.pdf.

Agamben, G. (2002), Homo Sacer: o poder do soberano e a vida nua I. UFMG. Tradução de Henrique Burigo.

Agamben, G. (2015), Meios sem fim. Notas sobre a política. Autêntica Editora. Tradução de Davi Pessoa Carneiro.

Alves, A. P. W., \& Barros, J. (2018). Racismo de Estado em Michel Foucault. Revista Profanações, 5(2), $179-191$.

Arendt, H. (2012). Origens do totalitarismo. Companhia das Letras.

Estadão. (2020). Manaus sofre com falta de caixões e corpos serão enterrados em sacos plásticos. ESTADÃO. https://noticias.uol.com.br/ultimasnoticias/agencia-estado/2020/04/28/manaus-quer-evitar-sepultamentos-em-sacos-plasticos.htm

Bathia, S., et al. (2020). Short-term forecasts of COVID-19 deaths in multiple countries. https://mrc-ide.github.io/covid19-short-term-forecasts/index.html.

Beiguelman, G. (2019). Memórias da amnésia. Políticas do esquecimento. Edições Sesc.

Castro-Gómez, S. (2007). Michel Foucault y la colonialidad del poder. Tabula Rasa, 6, 153-172

Césaire, Aimé. (1978). Discurso sobre o colonialismo. Livraria Sá da Costa Editora.

Costa, M, C, et al. (2009). O discurso colonizador na elaboração de projetos. Uma limitação ao desenvolvimento sustentável na Amazônia brasileira. http://www.bocc.ubi.pt/pag/agra-klondy-costa-discurso-colonizador.pdf.

Brasil. (2020). Decreto Legislativo n. 06/20 de 18 de março de 2020. Diário Oficial da União de 20.03.2020. Edição Extra - C.

Dejours, C.. (1999). A banalização da injustiça social. Editora FGV.

Estadão. (2020). Manifestantes fazem ato contra e em defesa da ditadura militar pelo Brasil. https://politica.estadao.com.br/noticias/geral,manifestantesfazem-atos-contra-e-em-defesa-da-ditadura-militar-pelo-brasil,70002774764.

Foucault, M. (1970). A ordem do discurso. Editora Loyola. Tradução de Laura Fraga de Almeida Sampaio.

Foucault, M. (1997). É preciso defender a sociedade. Curso no Collège de France. Martins Fontes.

Foucault, M. (2008). Arqueologia do saber. Forense Universitária. Tradução de Luiz Felipe Baeta Neves.

Franco, M. (2014). UPP a redução da favela a três letras. Uma análise da política de segurança pública do estado do Rio de Janeiro. Dissertação (Mestrado em Ciências Sociais). Rio de Janeiro: Universidade Federal Fluminense. Consultado a 28.04.2020, em https://app.uff.br/riuff/bitstream/1/2166/1/Marielle\%20Franco.pdf.

G1. (2020). Bolsonaro pede volta ao trabalho, 'observadas as normas do Ministério da Saúde', e diz que medidas de isolamento são 'responsabilidade exclusiva' dos governadores. https://g1.globo.com/politica/noticia/2020/04/08/bolsonaro-pede-volta-ao-trabalho-observadas-as-normas-do-ministerio-dasaude-e-diz-que-medidas-de-isolamento-sao-responsabilidade-exclusiva-dos-governadores.ghtml.

Leitão, M. (2020). Ódio de Weintraub pelo termo “povos indígenas” contraria a Constituição. Veja. https://veja.abril.com.br/blog/matheus-leitao/odio-deweintraub-pelo-termo-povos-indigenas-contraria-a-constituicao/

Losurdo, D. (2011). Como nasceu e como morreu o marxismo ocidental. Estudos de Sociologia, 16, 213-242. https://periodicos.fclar.unesp.br/estudos/article/view/3897

Mbembe, A. (2016). Necropolítica. Biopoder, soberania, estado de exceção, política da morte. Arte \& Ensaios, 32, 123-151. https://www.procomum.org/wpcontent/uploads/2019/04/necropolitica.pdf

Menezes, A. B. N. T. de. (2019). Rousseau e a crise do Estado de direito. Revista Dialectus, 15, 18-35. DOI: 10.30611/2019n15id43131.

Mignolo, Walter D. (2010). El pensamiento descolonial, desprendimento y apertura. Un manifesto.In: Linera, Álvaro Garcia et al. (Orgs.). Interculturalidad, descolonización del Estado y del conocimiento. Buenos Aires: Duke University, 83-123.

Gomes, P. H. (2020). Brasileiro pula em esgoto e não acontece nada, diz Bolsonaro em alusão a infecção pelo coronavírus. $O$ Globo. https://g1.globo.com/politica/noticia/2020/03/26/brasileiro-pula-em-esgoto-e-nao-acontece-nada-diz-bolsonaro-em-alusao-a-infeccao-pelo-coronavirus.ghtml. 
Research, Society and Development, v. 10, n. 8, e14810817302, 2021

(CC BY 4.0) | ISSN 2525-3409 | DOI: http://dx.doi.org/10.33448/rsd-v10i8.17302

Organização Mundial de Saúde. (2020). Folha informativa - COVID-19 (doença causada pelo novo coronavírus). https://www.paho.org/bra/index.php?option=com_content\&view=article\&id=6101:covid19\&Itemid=875.

Orlandi, E. P. (2007). Análise do Discurso: princípios e procedimentos. Pontes.

Pessanha, E. A. de M. (2018). Necropolítica e epistemicídio. As faces ontológicas da morte no contexto do racismo. Dissertação (Mestrado em Metafísica). Brasília: Universidade de Brasília. https://repositorio.unb.br/handle/10482/34771

Radioagência Nacional. (2020). Em pronunciamento, Bolsonaro critica governadores e fechamento de escolas. https://radioagencianacional.ebc.com.br/politica/audio/2020-03/em-pronunciamento-bolsonaro-critica-governadores-e-questiona-o-fechamento-de.

Santos, V. S. dos. (2014). O processo de ocupação de Rondônia e o impacto sobre as culturas indígenas. Itabaiana: GEPIADDE, 16, 187-220. https://seer.ufs.br/index.php/forumidentidades/article/view/4267

Souza, D. R. M. de. (2018). Estado de exceção. Giorgio Agamben entre Walter Benjamin e Carl Schmitt. Princípios: Revista de Filosofia (UFRN), 25(47), 35-58. 10.21680/1983-2109.2018v25n47ID12733

Stoler, A. L. (1995). Race and education of desire. Foucault's History of sexuality and the colonial order of things. London: Duke University Press.

Zygmunt, B. (2017). Estranhos à nossa porta. Zahar.

APIB. (2020). Arguição de descumprimento de preceito fundamental. http://www.stf.jus.br/arquivo/cms/noticiaNoticiaStf/anexo/adpf709.pdf

Acosta, A. (2016). O Bem Viver: uma oportunidade para imaginar outros mundos. Autonomia Literária, Elefante.

Cruz, S. R. da. (2020). Uma análise sobre o cenário da fome no Brasil em tempos de pandemia do COVID-19. Pensata, 09(02). https://doi.org/https://doi.org/10.34024/pensata.2020.v9.11104

Demenech, L. M., Dumith, S. de C., Vieira, M. E. C. D., \& Neiva-Silva, L. (2020). Desigualdade econômica e risco de infecção e morte por COVID-19 no Brasil. Revista Brasileira de Epidemiologia, 23. https://doi.org/https://doi.org/10.1590/1980-549720200095

Nascimento, A. do. (1978). O Genocídio do Negro Brasileiro: processo de um racismo mascarado. Paz e Terra.

Orlandi, E. (2005). Análise do Discurso: princípios e procedimentos. Pontes.

Peres, A. C. (2020). Favelas contra o vírus: como as periferias vêm lidando com a pandemia de COVID-19, em meio aos problemas cotidianos e diante da ausência de ações governamentais. RADIS, 212, 20-25. https://www.arca.fiocruz.br/bitstream/icict/41225/2/FavelasContraVirus.pdf

Rocha, D. F. da, \& Porto, M. F. S. (2020). A vulnerabilização dos povos indígenas frente ao COVID-19: autoritarismo político e a economia predatória do garimpo e da mineração como expressão de um colonialismo persistente. Núcleo Ecologias, Epistemologias e Promoção Emancipatória Da Saúde. https://portal.fiocruz.br/documento/ensaio-vulnerabilizacao-dos-povos-indigenas-frente-ao-COVID-19

Santos, M. P. A. dos, Nery, J. S., Goes, E. F., Silva, A. da, Santos, A. B. S. dos, Batista, L. E., \& Araújo, E. M. de. (2020). População negra e COVID-19: reflexões sobre racismo e saúde. Estudos Avançados, 34(99), 225-234. https://doi.org/10.1590/s0103-4014.2020.3499.014

Shalders, André. (2020). Passando a boiada: 5 momentos nos quais Ricardo Salles afrouxou regras ambientais. BBC NEWS BRASIL. https://www.bbc.com/portuguese/brasil-54364652

Trovão, C. J. B. M. (2020). A Pandemia da COVID-19 e a Desigualdade de Renda no Brasil: Um Olhar Macrorregional para a Proteção Social e os Auxílios Emergenciais. Universidade Federal do Rio Grande do Norte. https://ccsa.ufrn.br/portal/wp-content/uploads/2020/05/TROVÃO-2020-PANDEMIA-EDESIGUALDADE.pdf

UNCME. (2020). Educação em tempos de pandemia: direitos, normatização e controle social. https://www.unicef.org/brazil/media/9241/file 